\title{
ÉPOCA DE APLICAÇÃO DA PRIMEIRA DOSE DE NITROGÊNIO EM COBERTURA EM MILHO E ESPÉCIES ANTECESSORAS DE COBERTURA DE INVERNO(1)
}

\author{
Mércio Luiz Strieder ${ }^{(2)}$, Paulo Regis Ferreira da Silva ${ }^{(3)}$, Ibanor \\ Anghinoni $^{(4)}$, Egon José Meurer ${ }^{(4)}$, Lisandro Rambo ${ }^{(5)}$ \\ \& Paulo César Endrigo ${ }^{(6)}$
}

\begin{abstract}
RESUMO
Atualmente, os critérios utilizados no Sul do Brasil para definição da dose de nitrogênio (N) a ser aplicada no milho são o teor de matéria orgânica no solo, a expectativa de rendimento da cultura e as características da cultura antecessora. Embora apresente alta relação carbono:nitrogênio $(\mathrm{C} / \mathrm{N})$, a aveia preta é a espécie de cobertura de solo de inverno mais utilizada como antecessora às culturas comerciais de verão. Essa característica pode resultar em imobilização do $\mathrm{N}$ do solo, deficiência de $\mathrm{N}$ na planta de milho e redução no rendimento de grãos. Embora na determinação da dose a ser aplicada sejam consideradas as espécies antecessoras, os avanços quanto à melhor época para aplicar $\mathrm{N}$ em cobertura em milho foram pequenos. Com o objetivo de avaliar a época mais adequada para aplicação da primeira dose de $\mathrm{N}$ em cobertura no milho cultivado em sucessão a espécies de inverno com distintas relações $\mathrm{C} / \mathrm{N}$, um experimento foi realizado em vasos em casa de vegetação em Porto Alegre-RS. Utilizaram-se colunas de solo não deformado, classificado como Argissolo Vermelho distrófico típico. Os tratamentos
\end{abstract}

(1) Trabalho desenvolvido na disciplina Relação Solo-Planta (SOL 00206). Recebido para publicação em julho de 2005 e aprovado em setembro de 2006.

(2) Engenheiro-Agrônomo, Mestrando do Programa de Pós-Graduação em Fitotecnia, da Faculdade de Agronomia da Universidade Federal do Rio Grande do Sul - FA/UFRGS. Av. Bento Gonçalves 7712, Caixa Postal 15100, CEP 90001-970 Porto Alegre (RS). Bolsista do CNPq. E-mail: domercio@yahoo.com.br

(3) Professor Adjunto do Departamento de Plantas de Lavoura, FA/UFRGS. Pesquisador do CNPq. E-mail: paulo.silva@ufrgs.br

(4) Professor Adjunto do Departamento de Solos, FA/UFRGS. Pesquisador do CNPq. E-mail: ibanghi@ufrgs.br

(5) Engenheiro-Agrônomo, Desenvolvimento de Produtos. Syngenta Seeds Ltda., Rod. BR-452, Km 142+543 m. Caixa Postal 585, CEP 38400-974 Uberlândia (MG). E-mail: lisandrorambo@yahoo.com.br

(6) Estudante da Faculdade de Agronomia, Universidade Federal do Rio Grande do Sul - UFRGS. Bolsista de iniciação científica da FAPERGS. E-mail: endrigopc@yahoo.com.br 
constaram de quatro sistemas de coberturas de solo de inverno (aveia preta, ervilhaca comum, nabo forrageiro e pousio) e três formas de manejo de $\mathrm{N}$ em cobertura (com aplicação de $\mathrm{N}$ nos estádios $V_{3}$ ou $V_{5}$ e sem aplicação de $\mathrm{N}$ em cobertura). O delineamento experimental foi o completamente casualizado, em esquema fatorial $4 \times 3$, com três repetições. Procedeu-se à análise de variância pelo teste $F$ e à comparação de médias pelo teste de Tukey $(p<0,05)$. A aveia, que tem alta relação $\mathrm{C} / \mathrm{N}$, apresentou baixa taxa de mineralização e de liberação de $\mathrm{N}$ de seus resíduos, enquanto as culturas de ervilhaca comum e nabo forrageiro mostraram relação $\mathrm{C} / \mathrm{N}$ mais estreita, estimulando esses processos. Com o uso de aveia como cultura antecessora ao milho, verificou-se diminuição dos teores de $\mathbf{N}$ mineral no solo e de $\mathbf{N}$ total na planta de milho, independentemente da época de aplicação de $\mathrm{N}$ em cobertura, diminuindo o desenvolvimento inicial da planta. Em sucessão à ervilhaca comum e ao nabo forrageiro, o teor relativo de clorofila na folha e a produção de massa seca de milho, avaliados no estádio $V_{7}$, foram maiores em relação aos obtidos em sucessão à aveia preta, independentemente da época de aplicação da primeira dose de $\mathrm{N}$ em cobertura. Os dados obtidos evidenciaram ser possível retardar a época de aplicação da primeira dose de $\mathrm{N}$ em cobertura em milho do estádio $V_{3}$ para $V_{5}$, quando o milho for cultivado em sucessão a espécies de inverno com baixa relação $\mathrm{C} / \mathrm{N}$.

Termos de indexação: Zea mays, relação $\mathrm{C} / \mathrm{N}$, coberturas de solo de inverno, características de planta de milho e atributos químicos de solo.

\section{SUMMARY: TIMING OF FIRST SIDE-DRESSED NITROGEN APPLICATION IN MAIZE AS AFFECTED BY ANTECEDENT WINTER COVER SPECIES}

The criteria currently used in Southern Brazil for the definition of the nitrogen $(N)$ rate to be applied in maize are based on the soil organic matter content, the expected grain yield and the characteristics of the previous crop. Although the carbon:nitrogen $(C / N)$ ratio is high, black oat is the most commonly used winter species antecedent to commercial summer crops. This characteristic can result in soil $N$ immobilization, $N$ plant deficiency and reduced grain yield in maize. Although the antecedent species are considered in the determination of the adequate $N$ rate, little progress has been made regarding the best time for $N$ side dressed application in maize. With the objective of evaluating the best time of the first rate of $N$ side-dressed application in maize cultivated in succession to winter species with distinct $C / N$ ratios, a greenhouse experiment was conducted in pots in Porto Alegre, Rio Grande do Sul, Brazil. Undisturbed columns of soil, classified as typical dystrophic Argisol (Rhodic Ultisol) were used. The treatments consisted of four systems of winter cover species (black oat, common vetch, oilseed radish and fallow) and three management forms of side-dressed $N$ application ( $N$ applied in the growth stage $V_{3}, V_{5}$ and without $N$ application). The experimental design was a completely randomized block, in a $4 \times 3$ factorial treatment combination, with three replications. Analysis of variance was performed using the $F$ test and the treatment means were compared by Tukey's test $(p<0.05)$. Black oat, which has the highest $C / N$ ratio, presented the lowest rate of mineralization and $N$ release from its residues, while common vetch and oilseed radish have a lower $C / N$ ratio, stimulating the mineralization and $N$ release. Black oat preceding maize reduced the soil mineral $N$ and $N$ content in maize and affected the initial plant development, independent of the timing of $N$ side-dressed application. In maize succeeding common vetch and oilseed radish, the relative leaf chlorophyll content and the dry mass production of maize in the $V_{7}$ growth stage was higher in relation to that obtained in maize succeeding oat, independent of when the first rate of $N$ was side-dressed. The obtained data indicate that it is possible to delay the first side-dressed $N$ application in maize from $V_{3}$ to $V_{5}$ stage when maize is cultivated in succession to winter species with a low $\mathrm{C} / \mathrm{N}$ ratio.

Index terms: Zea mays, $C / N$ ratio, winter cover species, maize plant traits, soil chemical attributes. 


\section{INTRODUÇÃO}

Com a grande difusão do sistema plantio direto a partir da década de 90 no Sul do Brasil, a aveia preta (Avena strigosa) tornou-se a principal cultura de cobertura de solo de inverno, antecedendo as culturas comerciais de verão, principalmente soja e milho. Dentre suas vantagens, estão a facilidade de aquisição de sementes, o elevado rendimento de massa seca (MS) da parte aérea, o controle da erosão do solo, o aumento da infiltração de água e do conteúdo de carbono orgânico no solo, a ciclagem de nutrientes e o controle de plantas daninhas (Debarba \& Amado, 1997; Amado $\&$ Mielniczuk, 2000). Entretanto, como a aveia preta apresenta alta relação carbono:nitrogênio $(\mathrm{C} / \mathrm{N})$, ocorre imobilização do $\mathrm{N}$ do solo pela biomassa microbiana, diminuindo sua disponibilidade no solo, o que acarreta a deficiência, principalmente nos estádios iniciais de desenvolvimento do milho cultivado em sucessão. Trabalhos de Silva et al. (2002) demonstram que pode haver redução de cerca de $25 \%$ no rendimento de grãos do milho em sucessão à aveia preta, em relação ao cultivado após pousio de inverno (sem cobertura).

Para contornar essa situação, culturas alternativas, como ervilhaca comum (Vicia sativa) e nabo forrageiro (Raphanus sativus), estão sendo utilizadas, uma vez que, além de propiciarem cobertura ao solo, apresentam, respectivamente, potencial de fixação do $\mathrm{N}_{2}$ atmosférico em simbiose com Rhizobium e alta capacidade de reciclagem de $\mathrm{N}$ de camadas mais profundas para a superfície do solo. Segundo Stute \& Posner (1995), as espécies leguminosas podem promover melhor sincronia entre a liberação do $\mathrm{N}$ dos seus resíduos e as necessidades da planta de milho, em diferentes estádios de desenvolvimento, comparativamente às gramíneas. A decomposição dos resíduos dessas espécies reduz a necessidade de aporte de $\mathrm{N}$ mineral às culturas subseqüentes (Derpsch et al., 1985; Pavinato et al., 1994), prática particularmente importante no milho, por ser a adubação nitrogenada em cobertura parcela importante no seu custo de produção.

A recomendação atual de adubação nitrogenada para a cultura do milho em sistema semeadura direta nos Estados do Rio Grande do Sul e Santa Catarina preconiza a aplicação de 10 a $30 \mathrm{~kg} \mathrm{ha}^{-1} \mathrm{de} \mathrm{N}$ na semeadura e o restante em cobertura, quando a planta apresentar entre quatro $\left(\mathrm{V}_{4}\right)$ e seis $\left(\mathrm{V}_{6}\right)$ folhas expandidas (40 a $60 \mathrm{~cm}$ ) de estatura (CQFS RS/SC, 2004). Segundo essas indicações, para a definição da dose de $\mathrm{N}$ a ser aplicada em cobertura, devem-se considerar a expectativa de rendimento de grãos, o teor de matéria orgânica do solo e, mais recentemente, a espécie e seu rendimento de massa seca e as proporções das espécies, quando em cultivos consorciados. Apesar dos avanços quanto à definição da dose de $\mathrm{N}$ a ser aplicada no milho, a indicação vigente evoluiu pouco quanto à sua melhor época de aplicação. Isso é relevante, pois as espécies de cobertura de solo de inverno, utilizadas em cultivos solteiros ou em consórcios, apresentam taxa variável de decomposição dos resíduos culturais, sendo afetadas pela relação $\mathrm{C} / \mathrm{N}$ dos resíduos, pelo grau de lignificação e pelas condições do ambiente (temperatura do ar e umidade). Dessa forma, há necessidade de estudos mais detalhados para que esses aspectos sejam incluídos nos critérios para definição da época de aplicação de $\mathrm{N}$ em cobertura.

Em busca da otimização constante do sistema de indicação da adubação nitrogenada em milho, há grande potencial de inclusão de parâmetros de solo e de planta como indicadores complementares da disponibilidade de $\mathrm{N}$ no solo, principalmente em sistemas altamente produtivos e com aplicação de altas doses de N (Rambo et al., 2004). Esses indicadores têm sido utilizados para monitorar a disponibilidade de $\mathrm{N}$ e auxiliar na definição da dose e época de aplicação desse nutriente. Trabalhos de pesquisas realizados por Argenta (2001) e Rambo (2005) com a cultura do milho demonstram que há boa correlação entre teor relativo de clorofila na folha e o de $\mathrm{N}$ na folha com o rendimento de grãos. Rambo (2005) também verificou que o teor de nitrato no solo apresenta-se como potencial indicador complementar da disponibilidade de $\mathrm{N}$ no solo para manejo da adubação nitrogenada em milho, além do fato de a integração entre parâmetros de solo e de planta permitir aumento da eficiência de uso do $\mathrm{N}$ em lavouras, reduzindo a contaminação de recursos ambientais e o custo de produção.

Cerca de 60 e $40 \%$ do $\mathrm{N}$ presente na massa seca da ervilhaca comum e da aveia preta, respectivamente, são liberados de seus resíduos durante os primeiros 30 dias após seu manejo (Aita et al., 2001; Aita \& Giacomini, 2003). Assim, no milho cultivado em sucessão a espécies com alta liberação de $\mathrm{N}$ logo após seu manejo, pode-se admitir a redução no aporte de $\mathrm{N}$ nos estádios iniciais de desenvolvimento e, ou, retardar a época de aplicação da primeira dose de $\mathrm{N}$ em cobertura, estratégia que a atual indicação de $\mathrm{N}$ para o milho não considera. Com aplicação de $\mathrm{N}$ em estádios mais avançados de desenvolvimento, quando o sistema radical está mais desenvolvido, poder-se-ia melhorar o aproveitamento do $\mathrm{N}$ liberado pela cultura antecessora e do aplicado via adubação mineral, reduzindo perdas e contaminação dos recursos naturais, fato que é cada vez mais importante nos dias atuais ao se buscar sustentabilidade dos sistemas produtivos. Por outro lado, se o milho não for implantado logo após o manejo de culturas de cobertura de solo de inverno que apresentem alta liberação de N, presente em sua massa seca, parte significativa desse $\mathrm{N}$ pode ser perdida para camadas mais profundas do solo, tornando-se indisponível às plantas e causando impacto negativo no ambiente.

A hipótese desta pesquisa é de que a melhor época para aplicação da primeira dose de $\mathrm{N}$ em cobertura em milho depende de características da espécie de cobertura de solo de inverno antecessora, como sua capacidade em liberar $\mathrm{N}$ durante o ciclo da cultura em sucessão. 
Desse modo, os objetivos dessa pesquisa foram: (a) avaliar o desenvolvimento inicial da planta de milho, cultivado em sucessão a quatro sistemas de coberturas de solo de inverno, com diferentes relações $\mathrm{C} / \mathrm{N}$ de seus resíduos, e (b) avaliar a capacidade dessas espécies em suprirem as necessidades iniciais de $\mathrm{N}$ da planta e a possibilidade de se retardar a aplicação da primeira dose de $\mathrm{N}$ em sucessão a sistemas de cobertura de solo de inverno antecessoras com baixa relação $\mathrm{C} / \mathrm{N}$.

\section{MATERIAL E MÉTODOS}

O trabalho foi realizado entre setembro e dezembro de 2004, em casa de vegetação e nos laboratórios do Departamento de Plantas de Lavoura, da Faculdade de Agronomia, da Universidade Federal do Rio Grande do Sul (UFRGS), em Porto Alegre - RS (30 02 ' S, $51^{\circ} 13^{\prime} \mathrm{W}$, altitude média de $\left.10 \mathrm{~m}\right)$. Utilizaram-se vasos de PVC, com $15 \mathrm{~cm}$ de diâmetro, que continham $20 \mathrm{~cm}$ de coluna de solo não deformado, sendo mantidos os atributos do solo onde foi coletado. As colunas de solo foram coletadas logo após o manejo das espécies de cobertura de solo de inverno, na área experimental do referido departamento, onde as espécies vegetais estavam cultivadas. Essa área experimental localizase na Estação Experimental Agronômica da UFRGS, em Eldorado do Sul-RS, na região ecoclimática da Depressão Central do Estado do Rio Grande do Sul ( $30^{\circ} 05^{\prime} \mathrm{S}, 51^{\circ} 40^{\prime} \mathrm{W}$, altitude média de $\left.46 \mathrm{~m}\right)$. O clima da região é do tipo $\mathrm{Cfa}$, subtropical úmido, segundo a classificação de Köppen, predominante no Sul do Brasil, e segundo Bergamaschi et al. (2003), a precipitação média anual é de $1.467 \mathrm{~mm}$, sendo $463 \mathrm{~mm}$ concentrados nos meses de setembro a dezembro. Considerando o período experimental, na série histórica 1970/89, as médias de temperatura de solo e do ar e a umidade do ar foram de 20,9 e $20,0^{\circ} \mathrm{C}$ e 74,6\%, respectivamente (Bergamaschi et al., 2003).

A área de coleta do solo, onde são desenvolvidas outras pesquisas pelos autores, apresenta declividade média de $0,03 \mathrm{~m} \mathrm{~m}^{-1}$ e vem sendo utilizada no sistema semeadura direta desde 1993, adotando-se a rotação soja/milho, nos cultivos de verão, e de trigo e aveia preta/ervilhaca comum, nos de inverno. O solo da área experimental é classificado como Argissolo Vermelho distrófico típico (Embrapa, 1999). Durante a coleta das colunas de solo, amostrou-se o solo, considerando os seguintes atributos físicos e químicos: densidade do solo: $1.500 \mathrm{~g} \mathrm{dm}^{-3}$; argila: $510 \mathrm{~g} \mathrm{dm}^{-3}$; pH (água): 5,1; P(Mehlich-1): 5,6 mg dm${ }^{-3} ; \mathrm{K}$ (Mehlich-1): $111 \mathrm{mg} \mathrm{dm}^{-3}$; matéria orgânica: $20 \mathrm{~g} \mathrm{~kg}^{-1}$ e CTC: $8,8 \mathrm{cmol}_{\mathrm{c}} \mathrm{dm}^{-3}$, conforme descrito em Tedesco et al. (1995).

Os tratamentos constaram de quatro sistemas de coberturas de solo de inverno (ervilhaca comum, nabo forrageiro, aveia preta e pousio sem resíduos) e três formas de manejo de $\mathrm{N}$ em cobertura (aplicação de $\mathrm{N}$ em dois estádios de desenvolvimento do milho e um tratamento-testemunha, sem aplicação de $\mathrm{N}$ na cultura do milho em sucessão). O delineamento experimental foi o completamente casualizado, em esquema fatorial 4 x 3, com três repetições.

O estabelecimento das espécies de cobertura de solo de inverno na área experimental do Departamento de Plantas de Lavoura ocorreu em 25 de maio de 2004, enquanto o do híbrido simples Premium Flex, da Syngenta Seeds Ltda., nos vasos que continham as colunas de solo, em 27 de setembro de 2004. A data de semeadura do milho correspondeu a 14 dias após dessecação da aveia preta e ao dia de dessecação da ervilhaca comum, nabo forrageiro e do tratamento pousio. Adotou-se essa diferença entre os manejos das espécies para atrasar a época de semeadura do milho em sucessão à aveia preta em relação ao manejo dos demais sistemas de coberturas de solo de inverno, visando atenuar parte do efeito de imobilização de $\mathrm{N}$ da aveia preta sobre o milho, conforme indicações técnicas vigentes. Foram distribuídas 10 sementes em cinco covas por unidade experimental (vaso com coluna de solo), deixando-se apenas uma plântula por cova (cinco por vaso), por ocasião do desbaste, realizado no estádio de duas folhas expandidas $\left(\mathrm{V}_{2}\right)$. Dessas, coletaram-se três plantas no estádio $\mathrm{V}_{3}$ e as outras duas em $\mathrm{V}_{7}$, quando o experimento foi encerrado.

$\mathrm{O} \mathrm{N}$ em cobertura foi aplicado nos vasos nos estádios de três $\left(V_{3}\right)$ ou cinco $\left(V_{5}\right)$ folhas expandidas, conforme escala de desenvolvimento proposta por Ritchie et al. (1993), na dose de $88 \mathrm{mg}$ vaso-1 $^{-1}$, equivalente a $50 \mathrm{~kg} \mathrm{ha}^{-1}$, na forma de uréia ( $45 \%$ de $\mathrm{N}$ ). O tratamentotestemunha, sem aplicação de $\mathrm{N}$ em cobertura, objetivou avaliar a contribuição de cada cultura de inverno antecessora em fornecer $\mathrm{N}$ ao milho. As quantidades de MS de cada espécie de cobertura de solo de inverno adicionadas aos vasos que continham as colunas de solo não deformadas foram definidas com base no rendimento médio de MS, obtido, nos últimos cinco anos, na área experimental de coleta das colunas de solo, correspondentes a 4,20, 4,65 e 3,30 t ha ${ }^{-1}$, respectivamente, para aveia preta, nabo forrageiro e ervilhaca comum. Antes da instalação do experimento, os vasos com solo foram irrigados até atingir a capacidade de campo, condição mantida durante toda sua duração. Para isso, os vasos foram monitorados por meio de pesagens freqüentes ao longo do experimento, irrigando-se sempre que o peso era menor que o inicial.

A adubação na semeadura nos vasos constou da

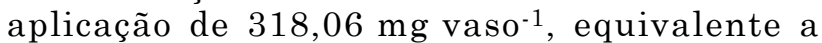
$180 \mathrm{~kg}$ ha ${ }^{-1}$ de $\mathrm{P}_{2} \mathrm{O}_{5}$ e de $\mathrm{K}_{2} \mathrm{O}$, respectivamente, nas formas de superfosfato triplo e cloreto de potássio. A quantidade de $\mathrm{N}$ aplicada na semeadura variou com $\mathrm{o}$ sistema de cobertura de solo de inverno, conforme indicações vigentes na cultura do milho (CQFS RS/SC, 2004). As doses corresponderam a $53,00 \mathrm{mg} \mathrm{vaso}^{-1}$, equivalente a $30 \mathrm{~kg} \mathrm{ha}^{-1}$ de $\mathrm{N}$, nos tratamentos com aveia preta e com pousio, e a $26,50 \mathrm{mg} \mathrm{vaso}^{-1}$, equivalente a $15 \mathrm{~kg} \mathrm{ha}^{-1}$ de $\mathrm{N}$, nos vasos com ervilhaca comum e nabo forrageiro. 
Determinaram-se as características relacionadas as coberturas de solo de inverno, o teor de $\mathrm{N}$ no solo e desenvolvimento inicial das plantas de milho. Nas coberturas de solo, as determinações constaram de: relação $\mathrm{C} / \mathrm{N}$ e teor de $\mathrm{N}$ nos resíduos nos estádios $\mathrm{V}_{0}$ (semeadura) e $\mathrm{V}_{7}$ (sete folhas expandidas), percentual de mineralização da MS das coberturas de solo de inverno e quantidade de $\mathrm{N}$ total liberada entre os estádios $\mathrm{V}_{0}$ e $\mathrm{V}_{7}$. No solo, determinou-se o teor de $\mathrm{N}$ mineral (nitrato e amônio) nos estádios $V_{3} \mathrm{eV}_{7}$. Nas plantas de milho foram avaliados o teor relativo de clorofila (TRC) na folha nos estádios $\mathrm{V}_{4} \mathrm{e} \mathrm{V}_{7}$, o teor de $\mathrm{N}$ na planta e o rendimento de MS da parte aérea e de raízes nos estádios $\mathrm{V}_{3} \mathrm{e} \mathrm{V}_{7}$.

Para determinação da MS dos resíduos das coberturas de solo de inverno e das plantas de milho, as amostras coletadas foram acondicionadas em estufa a $60{ }^{\circ} \mathrm{C}$, até atingir peso constante, quando foram pesadas. Posteriormente, foram moídas e homogeneizadas, para determinação do teor de $\mathrm{N}$ nos resíduos pelo método de Kjedahl, conforme descrito em Tedesco et al. (1995). O teor de $\mathrm{N}$ mineral no solo foi obtido pelo somatório dos teores de nitrato e amônio. $\mathrm{O}$ teor de carbono foi determinado por meio de destilação com dicromato de potássio, conforme descrito em Tedesco et al. (1995), enquanto o TRC na folha de milho foi avaliado com o equipamento clorofilômetro modelo Minolta SPAD-502 ${ }^{\circledR}$. Esse equipamento contém diodos que emitem luz a $650 \mathrm{~nm}$ (vermelho) e a $940 \mathrm{~nm}$ (infravermelho). A luz que passa através da amostra da folha atinge um receptor (fotodiodo de silicone) que a converte em sinais elétricos analógicos. Os valores obtidos são proporcionais ao teor relativo de clorofila na folha. As duas leituras por folha com clorofilômetro foram obtidas em pontos situados da metade a dois terços do comprimento da folha, a partir da base, e a dois centímetros da margem da folha, conforme descrito em Argenta (2001).
Os dados obtidos foram submetidos à análise de variância pelo teste $\mathrm{F}(\mathrm{p}<0,05)$. Quando alcançada significância estatística, as médias foram comparadas pelo teste Tukey $(\mathrm{p}<0,05)$.

\section{RESULTADOS E DISCUSSÃO}

\section{Características relacionadas com os sistemas de coberturas de solo de inverno}

Teor de $\mathbf{N}$ e relação $\mathrm{C} / \mathrm{N}$ dos resíduos: por ocasião da semeadura do milho $\left(\mathrm{V}_{0}\right)$, o teor de $\mathrm{N}$ nos resíduos foi maior na ervilhaca comum e no nabo forrageiro do que na aveia preta (Quadro 1). Por sua vez, a relação $\mathrm{C} / \mathrm{N}$ foi maior na aveia preta, não houve diferenças entre a ervilhaca comum e do nabo forrageiro. No estádio $V_{7}$, houve diferença entre o teor de $\mathrm{N}$ dos resíduos das três coberturas de solo de inverno, sendo o maior teor determinado na ervilhaca comum, e o menor, na aveia preta. A relação $\mathrm{C} / \mathrm{N}$ foi maior na aveia preta em relação às outras duas espécies, embora, nesse estádio, a relação $\mathrm{C} / \mathrm{N}$ do nabo forrageiro seja maior que a da ervilhaca comum. O aumento da relação $\mathrm{C} / \mathrm{N}$ no nabo forrageiro, no estádio $\mathrm{V}_{7}$ em relação ao $\mathrm{V}_{0}$, é atribuída à alta decomposição de folhas do nabo nos estádios iniciais de desenvolvimento do milho, as quais apresentam as maiores quantidades de $\mathrm{N}$ acumulada, enquanto os caules e ramos apresentam decomposição mais lenta, em virtude dos maiores teores de lignina, celulose $\mathrm{e}$ hemicelulose.

A relação $\mathrm{C} / \mathrm{N}$ é um dos principais parâmetros em modelos de predição da disponibilidade de $\mathrm{N}$ no solo através da decomposição dos resíduos orgânicos (Nicolardot et al., 2001). No presente estudo, quando

Quadro 1. Teor de nitrogênio e relação carbono:nitrogênio $(\mathrm{C} / \mathrm{N})$ nos resíduos de três espécies de cobertura de solo de inverno, nos estádios $V_{0}$ e $V_{7}$ do milho. Porto Alegre-RS, 2004

\begin{tabular}{|c|c|c|c|c|}
\hline \multirow{4}{*}{$\begin{array}{l}\text { Sistema de cobertura } \\
\text { de solo de inverno }\end{array}$} & \multicolumn{4}{|c|}{ Estádio de desenvolvimento do milho(1) } \\
\hline & \multicolumn{2}{|c|}{$\mathbf{V}_{0}$} & \multicolumn{2}{|c|}{$\mathrm{V}_{7}$} \\
\hline & Teor de $\mathbf{N}$ & Relação C/N & Teor de $\mathbf{N}$ & Relação C/N \\
\hline & $\mathrm{g} \mathrm{kg}^{-1}$ & & $\mathrm{~g} \mathrm{~kg}^{-1}$ & \\
\hline Ervilhaca comum & $31 \mathrm{a}^{(2)}$ & $13,0 \mathrm{~b}$ & $25 \mathrm{a}$ & $12,1 \mathrm{c}$ \\
\hline Nabo forrageiro & $34 \mathrm{a}$ & $11,0 \mathrm{~b}$ & $18 \mathrm{~b}$ & $19,5 \mathrm{~b}$ \\
\hline Aveia preta & $15 \mathrm{~b}$ & $28,1 \mathrm{a}$ & $13 \mathrm{c}$ & $24,4 \mathrm{a}$ \\
\hline CV (\%) & 2,4 & 3,5 & 2,1 & 22,1 \\
\hline
\end{tabular}


da semeadura do milho, os valores verificados na relação $\mathrm{C} / \mathrm{N}$ da ervilhaca comum e da aveia preta corroboram os de Giacomini et al. (2003), ao estudarem a importância de diferentes espécies de cobertura de solo de inverno. Entretanto, a relação $\mathrm{C} / \mathrm{N}$ do nabo forrageiro foi similar à determinada na ervilhaca comum, ao contrário daqueles autores, que, no nabo, obtiveram relação $\mathrm{C} / \mathrm{N}$ intermediária à da ervilhaca comum e à da aveia preta. Na avaliação realizada no estádio $\mathrm{V}_{7}$ do milho, os dados da relação $\mathrm{C} / \mathrm{N}$ do nabo foram intermediários aos das outras duas espécies, fato atribuído à decomposição de todas as suas folhas e talos mais finos, ao contrário da aveia preta, que revelou a taxa de decomposição bem mais lenta.

Mineralização dos resíduos das coberturas de solo de inverno: Nos tratamentos sem aplicação de $\mathrm{N}$ e com a aplicação de $\mathrm{N}$ no milho no estádio $\mathrm{V}_{3}$, ocorreu maior mineralização dos resíduos de nabo forrageiro em relação aos de ervilhaca comum e aveia preta (Quadro 2). A aplicação de $\mathrm{N}$, no estádio $\mathrm{V}_{5}$, aumentou a mineralização na ervilhaca comum em relação às outras duas espécies de cobertura de inverno. Na comparação entre os sistemas de manejo do $\mathrm{N}$ em cobertura, para a ervilhaca comum e aveia preta, ocorreu maior mineralização das coberturas de solo de inverno com aplicação de $\mathrm{N}$ no estádio $\mathrm{V}_{5} \mathrm{em}$ relação à não-aplicação de $\mathrm{N}$ em cobertura. No nabo forrageiro, a não-aplicação de $\mathrm{N}$ em cobertura e o retardo de sua aplicação do estádio $V_{3}$ para $V_{5}$ diminuíram a mineralização de resíduos. Nas três coberturas de solo de inverno, a não-aplicação de $\mathrm{N}$ em cobertura ou sua aplicação no estádio $V_{5}$ não diferiram da aplicação de $\mathrm{N}$ em cobertura no estádio $\mathrm{V}_{3}$. Esses dados confirmam os de Aita et al. (2001) e
Aita \& Giacomini (2003), que também obtiveram maior mineralização de resíduos e liberação de $\mathrm{N}$ nas primeiras quatro semanas após o manejo da ervilhaca comum e do nabo forrageiro, ao contrário da aveia preta, em que esses processos mostraram-se bem mais lentos.

Analisando as três formas de manejo de $\mathrm{N}$ em cobertura, notou-se que a maior quantidade de $\mathrm{N}$ disponibilizada pelos sistemas de coberturas de solo de inverno ao milho, avaliada no estádio $\mathrm{V}_{7}$, ocorreu em sucessão ao nabo forrageiro, seguido da ervilhaca comum e, posteriormente, da aveia preta (Quadro 2). Entre as formas de manejo de $\mathrm{N}$ em cobertura, na ervilhaca comum e na aveia preta, a maior disponibilidade de $\mathrm{N}$ ao milho ocorreu com sua aplicação nos estádios $V_{3}$ e $V_{5}$, em relação à nãoaplicação de N. No nabo forrageiro, não houve diferenças quanto ao $\mathrm{N}$ disponibilizado entre as três formas de manejo de N. Esses dados demonstram que, dependendo da espécie antecessora ao milho, o manejo do $\mathrm{N}$ em cobertura deve ser alterado, uma vez que, no caso do nabo e da ervilhaca comum, as quantidades de $\mathrm{N}$ disponibilizadas foram bem maiores que aquelas proporcionadas pela aveia preta. Além disso, a quantidade de $\mathrm{N}$ disponibilizada pelo nabo até o estádio $\mathrm{V}_{7}$ do milho foi cerca de 10 vezes superior ao da aveia preta, evidenciando a possibilidade de redução no dispêndio com aplicação de $\mathrm{N}$ em cobertura no milho ou seu retardo para estádios mais tardios. Entretanto, deve-se considerar que a aveia preta é importante na fase inicial de implantação do sistema de semeadura direta (Sá, 1996) e quando há necessidade de proteger melhor o solo da erosão, pois adiciona fitomassa e carbono e ajuda diminuir as perdas de $\mathrm{N}$ por lixiviação, sobretudo durante o outono/inverno, já que mantém o nutriente no tecido vegetal (Giacomini et al., 2003).

Quadro 2. Mineralização dos resíduos de três espécies de cobertura de solo de inverno e nitrogênio disponibilizado ao milho até o estádio $\mathrm{V}_{7}$, sob três espécies de coberturas de solo de inverno e três formas de manejo do N em cobertura no milho. Porto Alegre-RS, 2004
Sistema de cobertura
Sem aplicação de N Aplicação de N no milho (88 mg vaso-1)
de solo de inverno
no milho
Estádio $V_{3}(1)$
Estádio $V_{5}$

Mineralização das coberturas de inverno no estádio $\mathrm{V}_{7}(\%)(2)$

$\begin{array}{lccc}\text { Ervilhaca comum } & 10,3 \mathrm{~b} \mathrm{~B}^{(4)} & 15,7 \mathrm{~b} \mathrm{AB} & 25,9 \text { a A } \\ \text { Nabo forrageiro } & 29,6 \text { a A } & 23,9 \mathrm{a} \mathrm{AB} & 21,7 \mathrm{~b} \mathrm{~B} \\ \text { Aveia preta } & 8,6 \mathrm{~b} \mathrm{~B} & 14,7 \mathrm{~b} \mathrm{AB} & 18,6 \mathrm{~b} \mathrm{~A}\end{array}$

Quantidade de $\mathrm{N}$ disponibilizada ao milho até o estádio $\mathrm{V}_{7}\left(\mathrm{mg}\right.$ vaso-1) $^{-13}$

$\begin{array}{lrrr}\text { Ervilhaca comum } & 44,2 \mathrm{~b} \mathrm{~B} & 52,2 \mathrm{~b} \mathrm{AB} & 71,9 \mathrm{~b} \mathrm{~A} \\ \text { Nabo forrageiro } & 176,3 \text { a A } & 163,0 \text { a A } & 166,5 \text { a A } \\ \text { Aveia preta } & 14,3 \text { c B } & 20,8 \text { c A } & 16,3 \text { c AB }\end{array}$

(1) Conforme escala de desenvolvimento proposta por Ritchie et al. (1993). ${ }^{(2)}$ e (3) $\mathrm{CV}=20,0$ e $24,1 \%$, respectivamente. ${ }^{(4)}$ Para cada característica, médias seguidas de mesma letra minúscula, na coluna, e mesma letra maiúscula, na linha, não diferem entre si pelo teste de Tukey $(\mathrm{p}<0,05)$. 
Segundo Heinzmann (1985), Oliveira (1994), Amado et al. (2001) e Borkert et al. (2003), as diferenças no teor de $\mathrm{N}$ nas coberturas de solo de inverno e na taxa de liberação de nutrientes de seus resíduos são características intrínsecas de cada espécie e condicionam sua velocidade de decomposição pela biomassa do solo. Dentre essas características, destacam-se: a relação $\mathrm{C} / \mathrm{N}$, a proporção de caule e folhas e a composição bioquímica do tecido vegetal. Além disso, a velocidade de decomposição e de liberação de $\mathrm{N}$ dos resíduos culturais das coberturas de inverno é inversamente proporcional às relações $\mathrm{C} / \mathrm{N}$ e lignina/ $\mathrm{N}$ e diretamente proporcional aos teores de $\mathrm{N}$ na MS e de $\mathrm{N}$ e C da fração solúvel em água (Aita \& Giacomini, 2003). A adição de elevadas quantidades de resíduos com alta relação $\mathrm{C} / \mathrm{N}$ estimula a multiplicação gradativa de microrganismos no solo, que, ao decomporem a matéria orgânica, aumentam a produção de $\mathrm{CO}_{2}$ e imobilizam a maior parte do nitrato e amônio presente no solo (Victoria et al., 1992; Vargas et al., 2005).

A maior quantidade de $\mathrm{N}$ disponibilizada pela ervilhaca em relação à aveia preta deve-se à capacidade de a leguminosa fixar $\mathrm{N}_{2}$ atmosférico em simbiose com Rhizobium. Em razão das diferenças entre as espécies de cobertura de solo de inverno, o milho em sucessão à ervilhaca comum e ao nabo forrageiro deve ser semeado logo após a dessecação dessas, pois as perdas de $\mathrm{N}$ por lixiviação, volatilização e, ou, de nitrificação são potencializadas sob condições de precipitações elevadas ou com o atraso na época semeadura (Heinzmann, 1985; Aita et al., 2001; Giacomini et al., 2004; Silva et al., 2006). Por outro lado, Argenta et al. (1999) e Silva et al. (2006) reforçam que, em sucessão à aveia preta, há necessidade de um intervalo de cerca de 15 dias entre sua dessecação e a semeadura do milho, a fim de diminuir os efeitos negativos de possíveis compostos alelopáticos e da imobilização de $\mathrm{N}$ nos resíduos.

\section{Características relacionadas com o teor de $\mathrm{N}$ no solo}

No estádio $\mathrm{V}_{3}$, não houve diferença no teor de $\mathrm{N}$ mineral no solo entre a ervilhaca comum e o nabo forrageiro, mas os teores foram superiores aos verificados em sucessão ao pousio ou aveia preta (Quadro 3). O menor teor de N mineral no solo ocorreu, quando se utilizou aveia preta como cobertura de solo de inverno, enquanto, no tratamento pousio (sem cobertura de solo), ocorreram valores intermediários de $\mathrm{N}$ mineral no solo, demonstrando o efeito de imobilização de $\mathrm{N}$ da aveia preta em relação às demais coberturas de solo adotadas. A imobilização de parte do $\mathrm{N}$ do solo pela aveia preta reduz o desenvolvimento inicial do milho em sucessão e, posteriormente, seu rendimento de grãos (Silva et al., 2002 e 2006). Por esse motivo, em áreas onde o sistema semeadura direta tem menos de quatro anos (fase de implantação), devese aumentar o aporte de $\mathrm{N}$ na semeadura do milho (Sá, 1996), visando compensar parte do efeito negativo do aporte de resíduos culturais de alta relação $\mathrm{C} / \mathrm{N}$. Segundo esse autor, após essa fase inicial de alta imobilização de $\mathrm{Ne}$ e, portanto, de menor disponibilidade às plantas, inicia-se, lentamente, o restabelecimento do equilíbrio entre imobilização e mineralização, à medida que o aporte de resíduos culturais proporcionar acúmulo de $\mathrm{N}$ orgânico na camada superficial do solo.

$\mathrm{Na}$ avaliação no estádio $\mathrm{V}_{7}$ do milho, nos tratamentos sem aplicação de $\mathrm{N}$ em cobertura, o teor de $\mathrm{N}$ mineral no solo foi maior nos tratamentos com ervilhaca comum e em pousio, em relação ao nabo forrageiro e à aveia preta (Quadro 3). Com a aplicação de $\mathrm{N}$ no estádio $\mathrm{V}_{3}$ do milho, o teor de $\mathrm{N}$ mineral no solo foi maior nos vasos com ervilhaca comum e nabo forrageiro, e menor nos com aveia preta e no tratamento pousio. A aplicação de $\mathrm{N}$ no estádio $\mathrm{V}_{5}$ do milho resultou em maior teor de $\mathrm{N}$ mineral no solo no

Quadro 3. Teores de nitrogênio mineral no solo com milho no estádio $\mathrm{V}_{3}$, sob quatro sistemas de coberturas de solo de inverno, e no estádio $V_{7}$, sob quatro sistemas de coberturas de solo de inverno e três formas de manejo de N em cobertura. Porto Alegre-RS, 2004

\begin{tabular}{|c|c|c|c|c|}
\hline \multirow{3}{*}{$\begin{array}{l}\text { Sistema de cobertura } \\
\text { de solo de inverno }\end{array}$} & \multirow{3}{*}{$\begin{array}{c}\mathrm{N} \text { mineral } \\
\text { no solo em } V_{3}(2)\end{array}$} & \multicolumn{3}{|c|}{$\mathrm{N}$ mineral no solo em $V_{7}(3)$} \\
\hline & & \multirow{2}{*}{$\begin{array}{l}\text { Sem aplicação } \\
\text { de N no milho }\end{array}$} & \multicolumn{2}{|c|}{ Aplicação de N no milho (88 mg vaso-1) } \\
\hline & & & Estádio $V_{3}(1)$ & Estádio $V_{5}(3)$ \\
\hline & \multicolumn{4}{|c|}{ - Teores de $\mathrm{N}$ mineral no solo, $\mathrm{mg} \mathrm{kg}^{-1}$} \\
\hline Ervilhaca comum & $6,2 \mathrm{a}$ & 21,7 a $\mathrm{B}$ & 23,2 a B & 39,7 a $\mathrm{A}$ \\
\hline Nabo forrageiro & $6,1 \mathrm{a}$ & $18,4 \mathrm{~b} \mathrm{~B}$ & 22,6 a $\mathrm{B}$ & $31,7 \mathrm{~b} \mathrm{~A}$ \\
\hline Aveia preta & $2,7 \mathrm{c}$ & $19,4 \mathrm{~b} \mathrm{~A}$ & 19,6 b A & 21,6 с A \\
\hline Pousio & $4,7 \mathrm{~b}$ & 22,3 a $\mathrm{AB}$ & $19,6 \mathrm{~b} \mathrm{~B}$ & 23,6 с A \\
\hline
\end{tabular}

(1) Conforme escala de desenvolvimento proposta por Ritchie et al. (1993). ${ }^{(2)} \mathrm{CV}=13,4 \%$, e médias seguidas de mesma letra minúscula, na coluna, não diferem entre si pelo teste de Tukey $(\mathrm{p}<0,05) .{ }^{(3)} \mathrm{CV}=19,4 \%$, e médias seguidas de mesma letra minúscula, na coluna, e mesma letra maiúscula, na linha, não diferem entre si pelo teste de Tukey $(\mathrm{p}<0,05)$. 
tratamento em que o milho sucedeu à ervilhaca comum e o menor teor quando o milho foi cultivado em sucessão à aveia preta e ao pousio, com o nabo forrageiro ficando em posição intermediária. Isso demonstra que a aplicação de $\mathrm{N}$ no estádio $\mathrm{V}_{3}$ ou $\mathrm{V}_{5}$ favorece o desenvolvimento e o acúmulo de massa seca no milho em sucessão à ervilhaca comum e ao nabo (Quadro 7). Por sua vez, no milho em sucessão à aveia preta, há redução no acúmulo de massa seca, pois boa parte do $\mathrm{N}$ aplicado é imobilizada pelos seus resíduos ou pela biomassa microbiana do solo (Victoria et al., 1992; Vargas et al., 2005), ficando indisponível à planta. Apenas metade do $\mathrm{N}$ acumulado nos resíduos de aveia preta é liberada até 120 dias após seu manejo, o que equivale aproximadamente ao ciclo do milho, enquanto, nas leguminosas e no nabo forrageiro, essa liberação é superior a 80 \% (Aita et al., 2001).

No estádio $V_{7}$ do milho, não houve diferença entre as coberturas de solo de inverno quanto ao $\mathrm{N}$ mineral do solo entre a testemunha sem aplicação de $\mathrm{N}$ e com aplicação de $\mathrm{N}$ em $\mathrm{V}_{3}$ (Quadro 3). Com o atraso da aplicação de $\mathrm{N}$ do estádio $\mathrm{V}_{3}$ para $\mathrm{V}_{5}$, o teor de $\mathrm{N}$ mineral no solo aumentou, quando a cultura antecessora era a ervilhaca comum e o nabo forrageiro. No tratamento pousio, houve aumento em relação ao $\mathrm{V}_{3}$, mas não diferiu do tratamento sem $\mathrm{N}$. Não houve aumento do teor de $\mathrm{N}$ no solo, quando a cultura anterior era a aveia preta, demonstrando, novamente, a elevada imobilização de $\mathrm{N}$ pelos resíduos dessa espécie (Argenta et al., 1999; Aita et al., 2001). Embora o N mineral no solo, soma dos teores de nitrato + amônio + nitrito, seja reportado como importante na elaboração de recomendações de doses de $\mathrm{N}$ a serem aplicadas em cereais, pesquisas recentes obtiveram resultados contrários (Rambo, 2005). Segundo o autor, a adoção do teor de nitrato no solo seria suficiente, com potencial de ser usado como indicador complementar da disponibilidade de $\mathrm{N}$ no solo para manejo do $\mathrm{N}$ em milho, embora estudos mais conclusivos sejam necessários.

\section{Características relacionadas à planta de milho}

Teor de $\mathbf{N}$ na planta: no estádio $\mathrm{V}_{3}$, não houve diferença entre os sistemas de coberturas de solo de inverno quanto a essa característica (Quadro 4). Por outro lado, no estádio $\mathrm{V}_{7}$ do milho, nos tratamentos sem aplicação de $\mathrm{N}$ em cobertura, o maior teor de $\mathrm{N}$ na planta foi obtido nos tratamentos em sucessão ao nabo forrageiro, ao pousio e à ervilhaca comum, e o menor teor no milho em sucessão à aveia preta, embora essa não se diferencie da ervilhaca. Com a aplicação de $\mathrm{N}$ em $\mathrm{V}_{3}$, o maior teor de $\mathrm{N}$ nas plantas de milho foi obtido em sucessão ao nabo forrageiro e à ervilhaca comum e o menor em sucessão à aveia preta e ao tratamento pousio, embora esses dois não difiram do milho em sucessão à ervilhaca comum. Com aplicação de $\mathrm{N}$ em $\mathrm{V}_{5}$, o maior teor de $\mathrm{N}$ no milho foi verificado em sucessão ao pousio, e ao nabo, enquanto os menores valores foram obtidos após a ervilhaca comum e a aveia preta, os quais no entanto não diferem do nabo.

Esses resultados podem ser atribuídos à imobilização de $\mathrm{N}$ pelos resíduos das coberturas de solo, especialmente a aveia preta, enquanto no tratamento pousio o $\mathrm{N}$ aplicado ficou disponível às plantas. Devese considerar, ainda, que a biomassa microbiana tem efeito nesse comportamento por meio da imobilização de elevada quantidade de $\mathrm{N}$ do início ao fim do ciclo do milho (Victoria et al., 1992; Vargas et al., 2005), resultando em menor acúmulo de $\mathrm{N}$ em sua parte aérea. Assim, a biomassa microbiana atua mais como agente de mineralização do $\mathrm{N}$ orgânico do que como fonte de $\mathrm{N}$ potencialmente mineralizável, principalmente quando houver elevado aporte de resíduos com alta relação $\mathrm{C} / \mathrm{N}$, como é o caso da aveia preta.

Quadro 4. Teores de nitrogênio na planta de milho no estádio $\mathrm{V}_{3}$, sob quatro sistemas de coberturas de solo de inverno e no estádio $V_{7}$, sob quatro sistemas de coberturas de solo de inverno e três formas de manejo do N em cobertura. Porto Alegre-RS, 2004

\begin{tabular}{|c|c|c|c|c|}
\hline \multirow{3}{*}{$\begin{array}{c}\text { Sistema de cobertura } \\
\text { de solo de inverno }\end{array}$} & \multirow{3}{*}{$\begin{array}{c}\text { N mineral } \\
\text { no solo em } V_{3}(2)\end{array}$} & \multicolumn{3}{|c|}{$\mathrm{N}$ mineral no solo em $\mathrm{V}_{7}$} \\
\hline & & \multirow{2}{*}{$\begin{array}{l}\text { Sem aplicação } \\
\text { de N no milho }\end{array}$} & \multicolumn{2}{|c|}{ Aplicação de N no milho (88 mg vaso $\left.{ }^{-1}\right)$} \\
\hline & & & Estádio $V_{3}$ & Estádio $V_{5}$ \\
\hline & & \multicolumn{2}{|c|}{$-\%$} & + \\
\hline Ervilhaca comum & $3,9 \mathrm{a}$ & $1,3 \mathrm{ab} \mathrm{A}$ & $1,4 \mathrm{ab} \mathrm{A}$ & $1,6 \mathrm{~b} \mathrm{~A}$ \\
\hline Nabo forrageiro & $3,7 \mathrm{a}$ & 1,5 a $\mathrm{B}$ & 1,5 a $\mathrm{B}$ & $2,0 \mathrm{ab} \mathrm{A}$ \\
\hline Aveia preta & $3,9 \mathrm{a}$ & $1,0 \mathrm{~b} \mathrm{~B}$ & $1,2 \mathrm{~b} \mathrm{~B}$ & $1,7 \mathrm{~b} \mathrm{~A}$ \\
\hline Pousio & $3,9 \mathrm{a}$ & 1,4 a $\mathrm{B}$ & $1,3 \mathrm{~b} \mathrm{~B}$ & 2,5 a $\mathrm{A}$ \\
\hline
\end{tabular}

\footnotetext{
(1) Conforme escala de desenvolvimento proposta por Ritchie et al. (1993). (2) CV= 9,1\%, e médias seguidas de mesma letra minúscula, na coluna, não diferem entre si pelo teste de Tukey $(\mathrm{p}<0,05)$; ${ }^{(3)} \mathrm{CV}=9,4 \%$, e médias seguidas de mesma letra minúscula, na coluna, e mesma letra maiúscula, na linha, não diferem entre si pelo teste de Tukey ( $p<0,05$ ).
} 
Analisando as formas de manejo de $\mathrm{N}$ em cobertura, verificou-se que os valores do teor de $\mathrm{N}$ nas plantas de milho foram similares aos dos tratamentos sem aplicação de $\mathrm{N}$ e aos dos com a aplicação de $\mathrm{N}$ no estádio $\mathrm{V}_{3}$, independentemente do sistema de cobertura de inverno. $\mathrm{O}$ atraso da aplicação de $\mathrm{N}$ do estádio $\mathrm{V}_{3}$ para o estádio $\mathrm{V}_{5}$ somente não aumentou o teor de $\mathrm{N}$ na planta de milho em sucessão à ervilhaca comum. Isso evidencia que a ervilhaca comum apresenta capacidade de fornecer quantidade suficiente de $\mathrm{N}$ nos estádios iniciais de desenvolvimento da planta de milho, permitindo que a primeira aplicação de $\mathrm{N}$ em cobertura possa ser atrasada para estádios mais avançados de seu desenvolvimento.

Embora não avaliado no presente estudo, especulase que, mesmo usando ervilhaca comum como antecessora ao milho, seja necessário aplicar $\mathrm{N}$ em cobertura, pois o nitrogênio disponibilizado pela cobertura de solo tende a não atender às necessidades da planta durante o florescimento e enchimento de grãos. Para haver maior aproveitamento do N oriundo das plantas de cobertura de solo e do aplicado no milho via adubo mineral, é necessário ter sincronia entre a disponibilidade e, ou, aporte de $\mathrm{N}$ e sua demanda pela planta. Estudos têm verificado que os híbridos de milho contemporâneos apresentam maiores picos de absorção de $\mathrm{N}$ durante o espigamento e o enchimento de grãos (Rajcan \& Tollenaar, 1999; Silva et al., 2005), absorvendo mais de $50 \%$ do $\mathrm{N}$ requerido durante o ciclo nessa fase, o que evidencia mudanças na curva de absorção e de assimilação de $\mathrm{N}$, em relação aos genótipos lançados em décadas passadas. No presente estudo, ressalta-se a importância da ervilhaca comum e, para a maior parte dos parâmetros avaliados, do nabo forrageiro, como espécies que conseguem suprir boa parte das necessidades iniciais de $\mathrm{N}$ de milho, diferente do observado quando se utiliza a aveia preta como cobertura de solo de inverno.

Teor relativo de clorofila (TRC) na folha: a avaliação dessa característica de planta, por meio do clorofilômetro tem sido bastante estudada nos últimos anos, em virtude de sua rapidez, precisão e baixo custo. Este método fundamenta-se na correlação positiva entre teor de clorofila na folha e teor de $\mathrm{N}$ na planta (Argenta, 2001), a qual está associada à atividade fotossintética. Por estas vantagens e por estar correlacionada com rendimento de grãos, a determinação do TRC pelo clorofilômetro tem sido usada para predizer a necessidade de adubação nitrogenada na cultura do milho (Varvel et al., 1997; Argenta, 2001; Rambo, 2005).

Nos tratamentos sem aplicação de N, no estádio $\mathrm{V}_{4}$ do milho, o maior TRC na folha foi obtido nas plantas em sucessão à ervilhaca comum e o menor em sucessão à aveia preta (Quadro 5). Os TRCs na folha nos tratamentos em sucessão ao nabo forrageiro e ao tratamento pousio situaram-se numa posição intermediária. Quando se aplicou N em cobertura no estádio $\mathrm{V}_{3}$, o milho em sucessão à ervilhaca comum também apresentou maior TRC na folha em relação aos demais sistemas de coberturas de solo de inverno, que não diferiram entre si. Dentre as formas de manejo de $\mathrm{N}$ em cobertura, os TRCs na folha aumentaram apenas com aplicação de $\mathrm{N}$ no milho em sucessão à aveia preta. Isso confirma a elevada imobilização de N que ocorre com a utilização dessa espécie em relação aos demais sistemas de coberturas de inverno, como

Quadro 5. Teor relativo de clorofila (TRC) na folha de milho, nos estádios $\mathrm{V}_{4}$ e $\mathrm{V}_{7}$, sob quatro sistemas de coberturas de solo de inverno e três formas de manejo de N em cobertura. Porto Alegre-RS, 2004

\begin{tabular}{|c|c|c|c|}
\hline \multirow{2}{*}{$\begin{array}{l}\text { Sistema de cobertura } \\
\text { de solo de inverno }\end{array}$} & \multirow{2}{*}{$\begin{array}{l}\text { Sem aplicação } \\
\text { de N no milho }\end{array}$} & \multicolumn{2}{|c|}{ Aplicação de N no milho (88 mg vaso-1) } \\
\hline & & Estádio $V_{3}$ & Estádio $V_{5}$ \\
\hline & \multicolumn{3}{|c|}{ TRC na folha em $V_{4}^{(2)}$} \\
\hline Ervilhaca comum & 40,7 a $\mathrm{A}^{(3)}$ & 41,1 a $\mathrm{A}$ & $-(4)$ \\
\hline Nabo forrageiro & 39,5 b A & 39,2 b A & - \\
\hline Aveia preta & 37,8 с В & 39,0 b A & - \\
\hline \multirow[t]{2}{*}{ Pousio } & 38,8 b A & 38,7 b A & - \\
\hline & \multicolumn{3}{|c|}{ TRC na folha em $V_{7}{ }^{(2)}$} \\
\hline Ervilhaca comum & 32,8 b B & 37,4 a $\mathrm{A}$ & 38,8 b A \\
\hline Nabo forrageiro & 36,1 a $\mathrm{B}$ & 37,5 a $\mathrm{AB}$ & 41,4 a $\mathrm{A}$ \\
\hline Aveia preta & 28,2 с C & 33,7 b B & 35,6 с A \\
\hline Pousio & 32,5 b C & 36,0 a $\mathrm{B}$ & 37,9 b A \\
\hline
\end{tabular}


constataram Argenta et al. (1999), Aita et al. (2001) e Aita \& Giacomini (2003).

No estádio $V_{7}$, nos tratamentos sem $\mathrm{N}$ e com aplicação de $\mathrm{N}$ em cobertura em $\mathrm{V}_{5}$, os maiores TRCs na folha de milho foram obtidos em sucessão ao nabo forrageiro e os menores em sucessão à aveia preta (Quadro 5). Com aplicação de N no estádio $\mathrm{V}_{3}$, os TRCs na folha foram maiores no milho em sucessão à ervilhaca comum, ao nabo forrageiro e ao pousio em relação ao tratamento em sucessão à aveia preta. Observando as formas de manejo de $\mathrm{N}$ em cobertura, verificou-se que os TRCs na folha aumentaram à medida que se retardou a aplicação de $\mathrm{N}$ do estádio $\mathrm{V}_{3}$ para o $\mathrm{V}_{5}$ do milho cultivado em sucessão aos tratamentos pousio e aveia preta, demonstrando que essas espécies antecessoras não conseguem fornecer $\mathrm{N}$ suficiente para o desenvolvimento inicial da planta.

Como resultado do atraso da aplicação de $\mathrm{N}$ para estádios mais tardios, ocorreu diminuição da disponibilidade de $\mathrm{N}$ e do desenvolvimento inicial do milho em sucessão a esses dois sistemas de culturas de solo de inverno. Para a ervilhaca comum e o nabo forrageiro, não houve diferença entre a aplicação de $\mathrm{N}$ em $V_{3}$ ou em $V_{5}$, evidenciando ser possível atrasar a época de aplicação da primeira dose de $\mathrm{N}$ em cobertura para estádios mais avançados no milho em sucessão a essas duas espécies de cobertura de solo. Isso decorre da alta taxa de liberação de $\mathrm{N}$ dessas duas espécies (ervilhaca comum e nabo forrageiro) nos primeiros 30 dias após sua dessecação, atendendo às demandas iniciais do milho. Essa estratégia é importante para aumentar a eficiência de uso do $\mathrm{N}$ (EUN) aplicado com o adubo mineral e o disponibilizado pelas culturas antecessoras (Keeney, 1982), pois haveria maior sincronia entre o $\mathrm{N}$ disponibilizado e a necessidade das plantas em sucessão, diminuindo as perdas e a contaminação dos recursos naturais. Além disso, o monitoramento do nível de $\mathrm{N}$ na planta, com base no TRC na folha, também pode aumentar a EUN, especialmente quando são aplicadas altas doses desse nutriente (Rambo, 2005). Ressalta-se, entretanto, que, com uso de espécies com baixa relação $\mathrm{C} / \mathrm{N}$ e com alta taxa de mineralização, há necessidade de estabelecer a cultura em sucessão logo após seu manejo, evitando perdas expressivas de nutrientes por lixiviação.

Produção de massa seca (MS): no estádio $\mathrm{V}_{3}$, as produções de MS da parte aérea, de raízes e a produção total por vaso de milho foram maiores em sucessão à ervilhaca comum, comparativamente ao tratamento pousio, sem haver diferenças nos rendimentos em sucessão à aveia preta e ao nabo forrageiro (Quadro 6). A relação parte aérea/raízes foi maior no milho após à ervilhaca comum e à aveia preta, em relação ao pousio, com o nabo forrageiro situando-se em posição intermediária.

No estádio $V_{7}$ do milho, a maior produção de MS total por vaso foi obtida em sucessão à ervilhaca comum, independentemente da forma de manejo de $\mathrm{N}$ em cobertura (Quadro 7). No tratamento sem aplicação de $\mathrm{N}$ em cobertura, não houve diferença entre nabo forrageiro, aveia preta e o tratamento pousio. Entretanto, com a aplicação de $\mathrm{N}$ em cobertura em $\mathrm{V}_{3}$, obteve-se maior produção de MS total por vaso no milho, quando cultivado após pousio, em relação aos obtidos em sucessão ao nabo forrageiro e à aveia preta. Com aplicação de $\mathrm{N}$ no estádio $\mathrm{V}_{5}$, obteve-se maior produção de MS de milho em sucessão à ervilhaca comum, seguida pelo nabo forrageiro. A produção de MS de milho em sucessão a esses dois sistemas de coberturas de solo de inverno diferiu da obtida após à aveia preta e ao pousio, os quais não diferiram entre si.

Dentre as formas de manejo de $\mathrm{N}$ em cobertura, não houve diferença entre a aplicação de $\mathrm{N}$ em cobertura em $\mathrm{V}_{3}$ ou em $\mathrm{V}_{5}$ no milho em sucessão à ervilhaca comum e ao nabo forrageiro. Em sucessão

Quadro 6. Produção de massa seca da parte aérea, das raízes e total (parte aérea + raízes) por vaso e relação parte aérea/raízes em milho no estádio $V_{3}$ em sucessão a quatro sistemas de coberturas de solo de inverno. Porto Alegre-RS, 2004

\begin{tabular}{lcccc}
\hline \multirow{2}{*}{$\begin{array}{c}\text { Sistema de cobertura } \\
\text { de solo de inverno }\end{array}$} & \multicolumn{3}{c}{ Massa seca do milho(1 e 2) } & $\begin{array}{c}\text { Relação parte } \\
\text { aérea/raiz }\end{array}$ \\
\cline { 2 - 4 } & Parte aérea & Raiz & Total por vaso & \\
& & g vaso $^{-1}$ & & $0,95 \mathrm{a}$ \\
Ervilhaca comum & $1,4 \mathrm{a}^{(3)}$ & $1,4 \mathrm{a}$ & $2,8 \mathrm{a}$ & $0,90 \mathrm{ab}$ \\
Nabo forrageiro & $1,2 \mathrm{ab}$ & $1,3 \mathrm{ab}$ & $2,5 \mathrm{ab}$ & $0,96 \mathrm{a}$ \\
Aveia preta & $1,2 \mathrm{ab}$ & $1,2 \mathrm{ab}$ & $2,4 \mathrm{ab}$ & $0,84 \mathrm{~b}$ \\
Pousio & $1,0 \mathrm{~b}$ & $1,1 \mathrm{~b}$ & $2,1 \mathrm{~b}$ & 29,7 \\
CV (\%) & 13,6 & 31,2 & 27,1 &
\end{tabular}

\footnotetext{
$\overline{{ }^{(1)} \text { Conforme escala de desenvolvimento proposta por Ritchie et al. (1993). }{ }^{(2)} \text { Até esse estádio, o milho não recebeu adubação }}$ nitrogenada em cobertura. ${ }^{\left({ }^{3}\right)} \mathrm{Na}$ coluna, médias seguidas de mesma letra não diferem entre si pelo teste de Tukey $(\mathrm{p}<0,05)$.
} 
Quadro 7. Produção de massa seca (MS) total por vaso (parte aérea + raízes) de milho no estádio $\mathrm{V}_{7}$ em sucessão a quatro sistemas de coberturas de solo de inverno e três formas de manejo de $\mathrm{N}$ em cobertura, e relação parte aérea/raízes, sob quatro sistemas de coberturas de solo de inverno. Porto Alegre-RS, 2004

\begin{tabular}{ccccc}
\hline $\begin{array}{c}\text { Sistema de cobertura } \\
\text { de solo de inverno }\end{array}$ & $\begin{array}{c}\text { Sem aplicação } \\
\text { de N no milho }\end{array}$ & Aplicação de N no milho (88 mg vaso-1) & $\begin{array}{c}\text { Relação parte } \\
\text { aérea/raiz }\end{array}$ \\
\cline { 2 - 5 }
\end{tabular}

MS total da planta de milho no estádio $\mathrm{V}_{7}\left(\mathrm{~g}\right.$ vaso-1) $^{-13}$

$\begin{array}{lllll}\text { Ervilhaca comum } & 21,2 \mathrm{a} \mathrm{B}^{(4)} & 25,1 \mathrm{a} \mathrm{A} & 24,4 \mathrm{a} \mathrm{A} & 1,56 \mathrm{ab}^{(5)} \\ \text { Nabo forrageiro } & 15,6 \mathrm{~b} \mathrm{~A} & 16,0 \mathrm{c} \mathrm{A} & 16,8 \mathrm{~b} \mathrm{~A} & 1,64 \mathrm{a} \\ \text { Aveia preta } & 14,2 \mathrm{~b} \mathrm{~B} & 16,2 \mathrm{c} \mathrm{A} & 14,9 \mathrm{c} \mathrm{B} & 1,32 \mathrm{c} \\ \text { Pousio } & 14,1 \mathrm{~b} \mathrm{~B} & 18,5 \mathrm{~b} \mathrm{~A} & 14,9 \mathrm{c} \mathrm{B} & 1,45 \mathrm{bc}\end{array}$

\footnotetext{
$\overline{{ }^{(1)} \text { Conforme escala de desenvolvimento proposta por Ritchie et al. (1993). }{ }^{(2) \text { e (3) }} \mathrm{CV}=16,9 \text { e } 11,1 \% \text {, respectivamente. }{ }^{(4)} \text { Médias }}$ seguidas de mesma letra minúscula, na coluna, e mesma letra maiúscula, na linha, não diferem entre si pelo teste de Tukey $(p<0,05) .{ }^{(5)}$ Médias seguidas de mesma letra minúscula, na coluna, não diferem entre si pelo teste de Tukey $(p<0,05)$.
}

à aveia preta e ao pousio, a produção de MS total por vaso de milho diminuiu quando se atrasou a época de aplicação de $\mathrm{N}$ do estádio $\mathrm{V}_{3}$ para o estádio $\mathrm{V}_{5}$. Esses resultados também evidenciam que as indicações vigentes sobre a época de aplicação de $\mathrm{N}$ em milho devem levar em consideração as características da cultura antecessora, sendo possível retardar a aplicação de $V_{3}$ para $V_{5}$, quando em sucessão à ervilhaca comum e ao nabo forrageiro. Contudo, essa prática não é indicada quando o milho é cultivado em sucessão à aveia preta ou ao pousio ou quando o sistema semeadura direta está em fase de instalação (menos de quatro anos).

Tais resultados confirmam os obtidos por diversos autores (Silva et al., 2002; Aita et al. 2001; Heinrichs et al., 2001) que demonstram reduções no rendimento do milho quando cultivado em sucessão à aveia preta, fato atribuído à menor disponibilidade de $\mathrm{N}$ no solo pela imobilização desse na biomassa microbiana, sobretudo nos estádios iniciais de desenvolvimento do milho. Os autores ainda ressaltam que o uso da ervilhaca comum como antecessora ao milho favorece seu desenvolvimento e, portanto, seu rendimento final, fato atribuído ao $\mathrm{N}$ adicionado ao solo pela leguminosa, à fixação biológica de $\mathrm{N}$ e à sua menor relação $\mathrm{C} / \mathrm{N}$. No caso do nabo forrageiro, o $\mathrm{N}$ disponibilizado no início do desenvolvimento da cultura subseqüente é oriundo da sua grande capacidade de reciclagem de $\mathrm{N}$ de camadas mais profundas para a superfície do solo. A maior produção de MS do milho em sucessão deve-se, ainda, à facilidade de liberação de $\mathrm{N}$ durante a decomposição dos resíduos dessas duas espécies de cobertura.

\section{CONCLUSÕES}

1. A aveia preta apresentou baixa taxa de mineralização e de liberação de nitrogênio $(\mathrm{N})$ de seus resíduos, sendo esses processos estimulados nas espécies ervilhaca comum e nabo forrageiro.

2. A utilização de aveia preta como cultura antecessora ao milho diminuiu os teores de $\mathrm{N}$ mineral no solo e de N na planta de milho, independentemente da época de aplicação de $\mathrm{N}$ em cobertura.

3. A utilização de ervilhaca comum e nabo forrageiro, como espécies de cobertura de solo antecessoras, incrementou o teor relativo de clorofila na folha e a produção de massa seca de milho, avaliados no estádio de sete folhas expandidas, independentemente da época de aplicação de $\mathrm{N}$ em cobertura.

4. É possível retardar a época de aplicação da primeira dose de $\mathrm{N}$ em cobertura em milho do estádio de três para cinco folhas expandidas, quando em sucessão à ervilhaca comum ou ao nabo forrageiro.

\section{AGRADECIMENTOS}

Ao CNPq, pelas bolsas de produtividade em pesquisa e de pós-gradução. À FAPERGS, pela bolsa de iniciação científica. À empresa Syngenta Seeds, pelo apoio financeiro à presente pesquisa.

\section{LITERATURA CITADA}

AITA, C.; BASSO, C.J; CERETTA, C.A; GONÇALVES, C.N. \& DA ROS, C.O. Plantas de cobertura de solo como fonte de nitrogênio ao milho. R. Bras. Ci. Solo, 25:157-165, 2001.

AITA, C. \& GIACOMINI, S.J. Decomposição e liberação de nitrogênio de resíduos culturais de plantas de cobertura de solo solteiras e consorciadas. R. Bras. Ci. Solo, 27:601$612,2003$. 
AMADO, T.J.C.; BAYER, C.; ELTZ, F.L.P. \& BRUM, A.C.R Potencial de culturas de cobertura em acumular carbono e nitrogênio no solo no plantio direto e a melhoria da qualidade ambiental. R. Bras. Ci. Solo, 25:189-197, 2001.

AMADO, T.J.C. \& MIELNICZUK, J. Estimativa da adubação nitrogenada para o milho em sistemas de manejo e culturas de cobertura do solo. R. Bras. Ci. Solo, 24:179. $189,2000$.

ARGENTA, G. Monitoramento do nível de nitrogênio na planta como indicador da adubação nitrogenada em milho. Porto Alegre, Universidade Federal do Rio Grande do Sul, 2001. 112p. (Tese de Doutorado)

ARGENTA, G.; SILVA, P.R.F.; RIZZARDI, M.A.; BARUFFI, M.J. \& BEHEREGARAY NETO, V. Manejo do nitrogênio no milho em semeadura direta em sucessão a espécies de cobertura de solo no inverno e em dois locais. I - Efeito na absorção de N. Ci. Rural, 29:577-586, 1999.

BERGAMISCHI, H.; GUADAGNIN, M.R.; CARDOSO, L.S. \& SILVA, M.I.G. Clima da Estação Experimental da UFRGS (e região de abrangência). Porto Alegre, Universidade Federal do Rio Grande do Sul, 2003. 77p.

BORKERT, C.M.; GAUDÊNCIO, C.A.; PEREIRA, J.E.; PEREIRA, L.R. \& OLIVEIRA Jr., A. Nutrientes minerais na biomassa da parte aérea em culturas de cobertura de solo. Pesq. Agropec. Bras., 38:143-153, 2003.

COMISSÃO DE QUÍMICA E FERTILIDADE DO SOLO - CQFS RS/SC). Manual de adubação e de calagem para os Estados do Rio Grande do Sul e Santa Catarina. Porto Alegre, Sociedade Brasileira de Ciência do Solos, Núcleo Regional Sul, 2004. 400p.

DEBARBA, L. \& AMADO, T.J.C. Desenvolvimento de sistemas de produção de milho no Sul do Brasil com características de sustentabilidade. R. Bras. Ci. Solo, 21:473-480, 1997.

DERPSCH, R.; SIDIRAS, N. \& HEINZMANN, F.X. Manejo do solo com coberturas verdes de inverno. Pesq. Agropec. Bras., 20:761-773, 1985.

EMPRESA BRASILEIRA DE PESQUISA AGROPECUÁRIA EMBRAPA. Centro Nacional de Pesquisa de Solos. Sistema Brasileiro de Classificação de Solos. Brasília, Embrapa Produção da Informação. Rio de Janeiro, Embrapa Solos, 1999. 412p.

GIACOMINI, S.J.; AITA, C.; CHIAPINOTTO, I.C.; HÜBNER, A.P.; MARQUES, M.G. \& CADORE, F. Consorciação de plantas de cobertura antecedendo o milho em plantio direto. II - Nitrogênio acumulado pelo milho e produtividade de grãos. R. Bras. Ci. Solo, 28:751-762, 2004.

GIACOMINI, S.J.; AITA, C.; VENDRUSCOLO, E.R.O.; CUBILLA, M.; NICOLOSO, R.S. \& FRIES, M.R. Matéria seca, relação $\mathrm{C} / \mathrm{N}$ e acúmulo de nitrogênio, fósforo $\mathrm{e}$ potássio em misturas de plantas de cobertura de solo. R. Bras. Ci. Solo, 27:325-334, 2003.

HEINRICHS, R.; AITA, C.; AMADO, T.J.C. \& FANCELLI, A.L. Cultivo consorciado de aveia preta e ervilhaca: relação C/ $\mathrm{N}$ da fitomassa e produtividade do milho em sucessão. $\mathrm{R}$. Bras. Ci. Solo, 25:331-340, 2001.

HEINZMANN, F.X. Resíduos culturais de inverno e assimilação de nitrogênio por culturas de inverno. Pesq. Agropec. Bras., 20:1021-1030, 1985.

KEENEY, D.R. Nitrogen management for maximum efficiency and minimum pollution. In: STEVENSEN, F.J., ed. Nitrogen in agricultural soils. Madison, Soil Science Society of America, 1982. p.605-649.
NICOLARDOT, B.; RECOUS, S. \& MARY, B. Simulation of C and $\mathrm{N}$ mineralization during crop residue decomposition: A simple dynamic model based on the $\mathrm{C} / \mathrm{N}$ ratio of the residues. Plant Soil, 228:83-103, 2001.

OLIVEIRA, E.L. Coberturas verdes de inverno e adubação nitrogenada em algodoeiro. Pesq. Agropec. Bras., 18:235241, 1994

PAVINATO, A.; AITA, C.; CERETTA, C.A. \& BEVILAQUA, G.P. Resíduos culturais de espécies de inverno e rendimento de grãos de milho no sistema de cultivo mínimo. Pesq. Agropec. Bras., 29:1427-1432, 1994.

RAJCAN, I. \& TOLLENAAR, M. Source: Sink ratio leaf senescence in maize. I. Dry matter and partitioning during grain filling. Field Crops Res., 60:245-253, 1999.

RAMBO, L.; SILVA, P.R.F. \& BAYER, C. Testes de nitrato no solo como indicadores complementares no manejo da adubação nitrogenada em milho. Ci. Rural, 34:1279-1287, 2004.

RAMBO, L. Integração de características de planta, de dossel e de solo para maior eficiência da adubação nitrogenada em cobertura em milho. Porto Alegre, Universidade Federal do Rio Grande do Sul, 2005. 178p. (Tese de Doutorado)

RITCHIE, S.W.; HANWAY, J.J. \& BENSON, G.O. How a corn plant develops. Ames, Iowa State University of Science and Technology, Cooperative Extension Service, 1993. 21p. (Special Report, 48). Disponível no site: www.maize.agron.iastate.edu/corngrows.html.

SÁ, J.C.M. Manejo de nitrogênio na cultura do milho no sistema de plantio direto. Passo Fundo, Aldeia Norte, 1996. 24p.

SILVA, P.R.F.; ARGENTA, G.; SANGOI, L.; STRIEDER, M.L. \& SILVA, A.A. Estratégias de manejo de coberturas de solo no inverno para cultivo do milho em sucessão no sistema semeadura direta. Ci. Rural, 36:1011-1020, 2006.

SILVA, P.R.F.; STRIEDER, M.L.; SILVA, R.P.C.; RAMBO, L.; SANGOI, L.; ARGENTA, G.; FORSTHOFER, E.L. \& SILVA, A.A. Grain yield and kernel crude protein content increases of maize hybrids with late nitrogen sidedressing. Sci. Agric., 62:487-492, 2005.

SILVA, P.R.F.; ARGENTA, G.; BARNI, N.A.; SUBRE, E.; FORSTHOFER, E.L.; STRIEDER, M.L. \& JERCHMANN, L.L. Sistemas de cobertura de solo no inverso e seus efeitos sobre o rendimento de grãos de milho em dois ambientes contrastantes. In: CONGRESSO BRASILEIRO DO MILHO E SORGO, 24., Florianópolis, 2002. Resumos Expandidos. Embrapa/CNMS/Epagri, 2002. CD-ROOM

STUTE, J.K. \& POSNER, J.L. Synchrony between legume nitrogen release and corn demand in the Upper Midwest. Agron. J., 87:1063-1069, 1995.

TEDESCO, M.J.; GIANELLO, C.; BISSANI, C.A.; VOLKWEISS, S.J. \& BOHNEN, H. Análises de solo, plantas e outros materiais. 2.ed. Porto Alegre, Universidade Federal do Rio Grande do Sul, 1995. 174p.

VARGAS, L.K.; SELBACH, P.A. \& SÁ, E.L.S. Imobilização de nitrogênio em solo cultivado com milho em sucessão à aveia preta nos sistemas plantio direto e convencional. Ci. Rural, 35:76-83, 2005.

VARVEL, G.E.; SCHEPERS, J.S. \& FRANCIS, D.D. Ability for in-season correction of nitrogen deficiency in corn using chlorophyll meter. Soil Sci. Soc. Am. J., 61:1233-1239, 1997.

VICTORIA, R.L.; PICCOLO, M.C. \& VARGAS, A.A.T. O ciclo do nitrogênio. In: CARDOSO, E.J.B.N.; TSAI, S.M. \& NEVES, M.C.P., coords. Microbiologia do solo. Campinas, Sociedade Brasileira de Ciência do Solo, 1992. p.105-120. 